\title{
Rhodoplanes gen. nov., a New Genus of Phototrophic Bacteria Including Rhodopseudomonas rosea as Rhodoplanes roseus comb. nov. and Rhodoplanes elegans sp. nov.
}

\author{
AKIRA HIRAISHI* AND YOKO UEDA \\ Laboratory of Environmental Biotechnology, Konishi Co., Yokokawa, Sumida-ku, Tokyo 130, Japan
}

\begin{abstract}
Two new strains (AS130 and AS140) of phototrophic purple nonsulfur bacteria isolated from activated sludge were characterized and compared with Rhodopseudomonas rosea and some other species of the genus Rhodopseudomonas. The new isolates produced pink photosynthetic cultures, had rod-shaped cells that divided by budding, and formed intracytoplasmic membranes of the lamellar type together with bacteriochlorophyll $a$ and carotenoids of the normal spirilloxanthin series. They were also characterized by their capacity for complete denitrification and their production of both ubiquinone-10 and rhodoquinone-10 as major quinones. The isolates were phenotypically most similar to $R$. rosea but exhibited low levels of genomic DNA hybridization to this species and to all other Rhodopseudomonas species compared. Phylogenetic analyses on the basis of PCR-amplified 16S rRNA gene sequences showed that our isolates and $R$. rosea formed a cluster distinct from other members of the genus Rhodopseudomonas. The phenotypic, genotypic, and phylogenetic data show that the new isolates and $R$. rosea should be placed in a new single genus rather than included in the genus Rhodopseudomonas. Thus, we propose to transfer $R$. rosea to a new genus, Rhodoplanes, as Rhodoplanes roseus gen. nov., comb. nov. (type species) and to designate strains AS130 and AS140 a new species, Rhodoplanes elegans sp. nov.
\end{abstract}

Species of the genus Rhodopseudomonas, which constitute a major group of phototrophic purple nonsulfur bacteria belonging to the alpha subclass of the class Proteobacteria, are characterized by having a budding cell morphology and forming intracytoplasmic membranes of the lamellar type $(16,32)$. In spite of their morphological and structural similarities, Rhodopseudomonas species are phylogenetically quite diverse. Comparisons of rRNA, i.e., DNA-rRNA hybridization and $16 \mathrm{~S}$ rRNA cataloging and sequencing, have demonstrated that these bacteria belong to several different lines of descent within the alpha-2 subclass of the Proteobacteria $(2,33,34)$. Exceptionally, Rhodopseudomonas blastica is a member of the alpha-3 subclass, closely related to Rhodobacter species (14, 18 ), and this situation has led to the proposal for transfer of $R$. blastica to the genus Rhodobacter (18). The phenotypic and chemotaxonomic heterogeneity in the genus Rhodopseudomonas has been summarized by Imhoff et al. (16).

As suggested by their phylogenetic heterogeneity, the color of phototrophic cell suspensions of Rhodopseudomonas strains differs from species to species, depending upon bacteriochlorophyll types and carotenoid compositions. Thus, this trait is of value for the classification and identification of these species. Mass cultures of the type species Rhodopseudomonas palustris and Rhodopseudomonas acidophila (26) are red to brownish red; those of the species with bacteriochlorophyll $b$, Rhodopseudomonas viridis (3) and Rhodopseudomonas sulfoviridis (19), are green; and those of the marine species Rhodopseudomonas marina (15) and the recently described freshwater species Rhodopseudomonas rosea (17) are pink.

Activated sludge and other wastewater environments are constant sources of the purple nonsulfur bacteria $(10,12,31)$. During the course of ecological studies on phototrophic bacteria in activated sludge, we isolated some strains of facultative

\footnotetext{
* Corresponding author. Present address: Central Research Laboratories (LK), Ajinomoto Co., Inc., Suzuki-cho 1-1, Kawasaki-ku, Kawasaki 210, Japan. Phone: 044-244-7181. Fax: 044-246-2867.
}

phototrophs that produced pink cultures and a cell morphology typical of the genus Rhodopseudomonas. The new isolates most closely resembled $R$. rosea with respect to general morphology, pigmentation, and natural habitats. In the present study, the new pink isolates were characterized phenotypically, genotypically, and phylogenetically and compared with $R$. rosea and some other known members of the genus Rhodopseudomonas. In this report, we propose to transfer $R$. rosea to a new genus, Rhodoplanes, and to designate a new species of this genus for our isolates.

\section{MATERIALS AND METHODS}

Bacterial strains and cultivation. Two pink-pigmented strains (designated AS130 and AS140) of the purple nonsulfur bacteria isolated from activated sludge were studied. $R$. rosea $941^{\mathrm{T}}(\mathrm{T}=$ type strain) was kindly provided by C. G. Harfoot, University of Waikato, Hamilton, New Zealand. $R$. acidophila ATCC $25092^{\mathrm{T}}, R$. blastica ATCC $33485^{\mathrm{T}}, R$. marina DSM $2698^{\mathrm{T}}, R$. palustris ATCC $17001^{\mathrm{T}}$, RS22, SA37, SA42, Tb, and HLS2, and $R$. viridis ATCC $19567^{\mathrm{T}}$ were also used for comparison. The strains with ATCC and DSM numbers were obtained, respectively, from the American Type Culture Collection, Rockville, Md., and from the Deutsche Sammlung von Mikroorganismen und Zellkulturen $\mathrm{GmbH}$, Braunschweig, Germany. The $R$. palustris strains other than the type strain were isolated from various environments, including sewage, waste sludge, pond water, and soil $(10,11)$. A chemically defined medium (designated PYS medium) which consisted of mineral base RM2 (pH 6.8) (10), 20 mM pyruvate (filter sterilized) as the sole carbon source, and $0.1 \%$ yeast extract as the growth factor was used for cultivation of the organisms to be subjected to various tests. In some cases, MYCA medium (9) was used for growth of organisms other than our new isolates and $R$. rosea. The culture media were modified by lowering the $\mathrm{pH}$ to 5.5 for $R$. acidophila and by adding $2.5 \%$ $\mathrm{NaCl}$ for $R$. marina. Routine cultivation was done anaerobically in screw-capped test tubes or bottles filled with medium; 


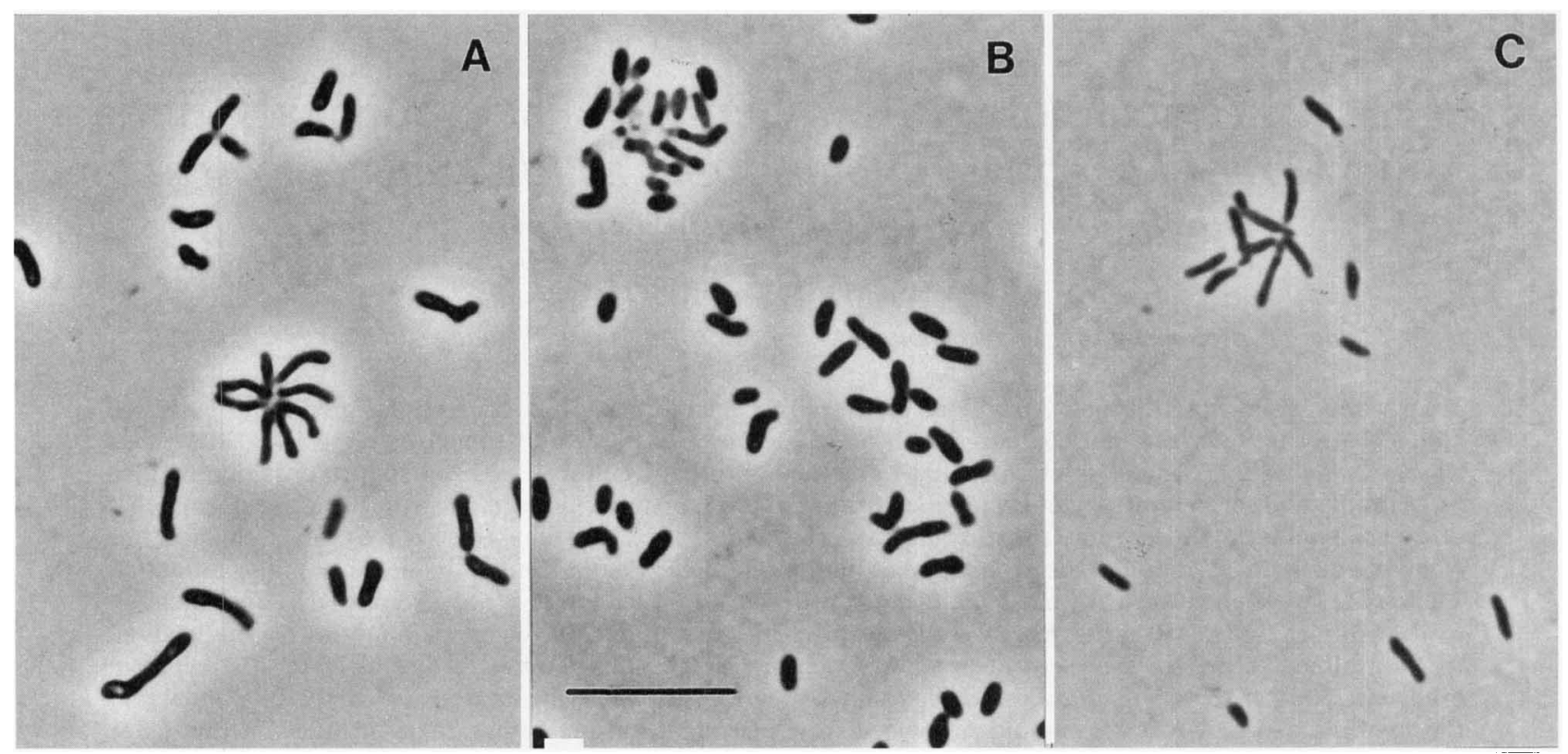

FIG. 1. Phase-contrast micrographs showing cell morphology of strain AS130 (A), R. rosea $941^{\mathrm{T}}(\mathrm{B})$, and R. palustris $\mathrm{ATCC} 17001^{\mathrm{T}}$ (C). Bar, $10 \mu \mathrm{m}$.

incubation was at $30^{\circ} \mathrm{C}$ and $5,000 \mathrm{~lx}$ of incandescent illumination. For genetic studies, cells were harvested by centrifugation from cultures at the mid-exponential phase of growth, washed with sterilized $1 \%$ saline, resuspended either in pure water for PCR experiments or in EDTA-saline for DNA hybridization studies, and stored at $-20^{\circ} \mathrm{C}$ until they were used.

Phenotypic characterization. Morphology and related properties were studied under an Olympus phase-contrast microscope and a JEOL transmission electron microscope. The photosynthetic membrane arrangement of cells was determined by electron microscopy of ultrathin sections as described previously (9). Absorption spectra of intact cells or cell extracts were measured with a Hitachi U-2000 spectrophotometer. Aerobic growth in darkness was determined in $100-\mathrm{ml}$ flasks containing $10 \mathrm{ml}$ of PYS medium on a reciprocal shaker. Anaerobic growth by nitrate respiration was determined in screw-capped test tubes completely filled with PYS medium supplemented with $20 \mathrm{mM}$ potassium nitrate. $\mathrm{N}_{2}$ gas production by complete denitrification was observed in these test tubes, with Durham tubes compared with a negative control without nitrate. Tests for photoassimilation of organic substrates were performed in screw-capped test tubes containing mineral base medium RM2 supplemented with a neutralized, filter-sterilized, organic compound as the carbon source and $0.01 \%$ yeast extract as the growth factor. Photoautotrophic growth was determined with the mineral medium supplemented with either $0.5 \mathrm{mM}$ sodium sulfide or $2 \mathrm{mM}$ sodium thiosulfate as the electron donor, $20 \mathrm{mM}$ sodium bicarbonate (filter sterilized), and $0.01 \%$ yeast extract. In all growth response tests, growth was monitored turbidometrically with an ANA-75 spectrophotometer (Tokyo Photoelectric Co., Tokyo, Japan), and the final reading was taken after 2 weeks of incubation. All other physiological and biochemical tests were performed as described elsewhere $(10,11)$. Quinones were extracted with an organic solvent mixture, purified by thinlayer chromatography, and analyzed by high-performance liquid chromatography (HPLC) (8).

DNA base composition and DNA-DNA hybridization.
Genomic DNA was extracted and purified according to the method of Marmur (23). DNA base composition was determined by HPLC of nuclease P1 hydrolysates of DNA with external nucleotide standards as previously reported (9). Genomic DNA reassociation studies were performed by the quantitative dot blot hybridization method with photobiotin labeling and colorimetric detection $(4,9)$.

PCR amplification and sequencing of 16S rRNA gene. 16S ribosomal DNA (rDNA) fragments that corresponded to positions 8 to 1510 of Escherichia coli 16S rRNA (1) were amplified by PCR from crude cell lysates and sequenced directly by the cycle sequencing method modified for automated fluorescence detection. The reactions were analyzed with a Pharmacia laser fluorescent DNA sequencer. Detailed information concerning the PCR and sequencing procedures used has been given previously $(7,13)$.

Phylogenetic analysis. Compiling of sequence data and calculation of levels of binary sequence similarities were performed with an Apple Macintosh personal computer with the GENETYX program package (Software Development Co., Tokyo, Japan). The CLUSTAL V program (6) was used for multiple sequence alignment, calculation of nucleotide substitution rates $\left(K_{\text {nuc }}\right)(20)$, construction of a neighborjoining phylogenetic tree (27), and statistical evaluation of the tree topology by bootstrap analysis (5). Alignment positions including gaps and/or unidentified bases were not taken into consideration for the calculations.

Nucleotide sequence accession numbers. The 16S rDNA sequences determined in the present study have been deposited in the DDBJ, EMBL, GSDB, and NCBI nucleotide sequence databases under accession numbers D25311 to D25314.

\section{RESULTS}

Isolation. A sample of activated sludge was taken from the main purification stage of a sewage treatment plant in Tokyo, Japan, and examined promptly upon return to the laboratory. 

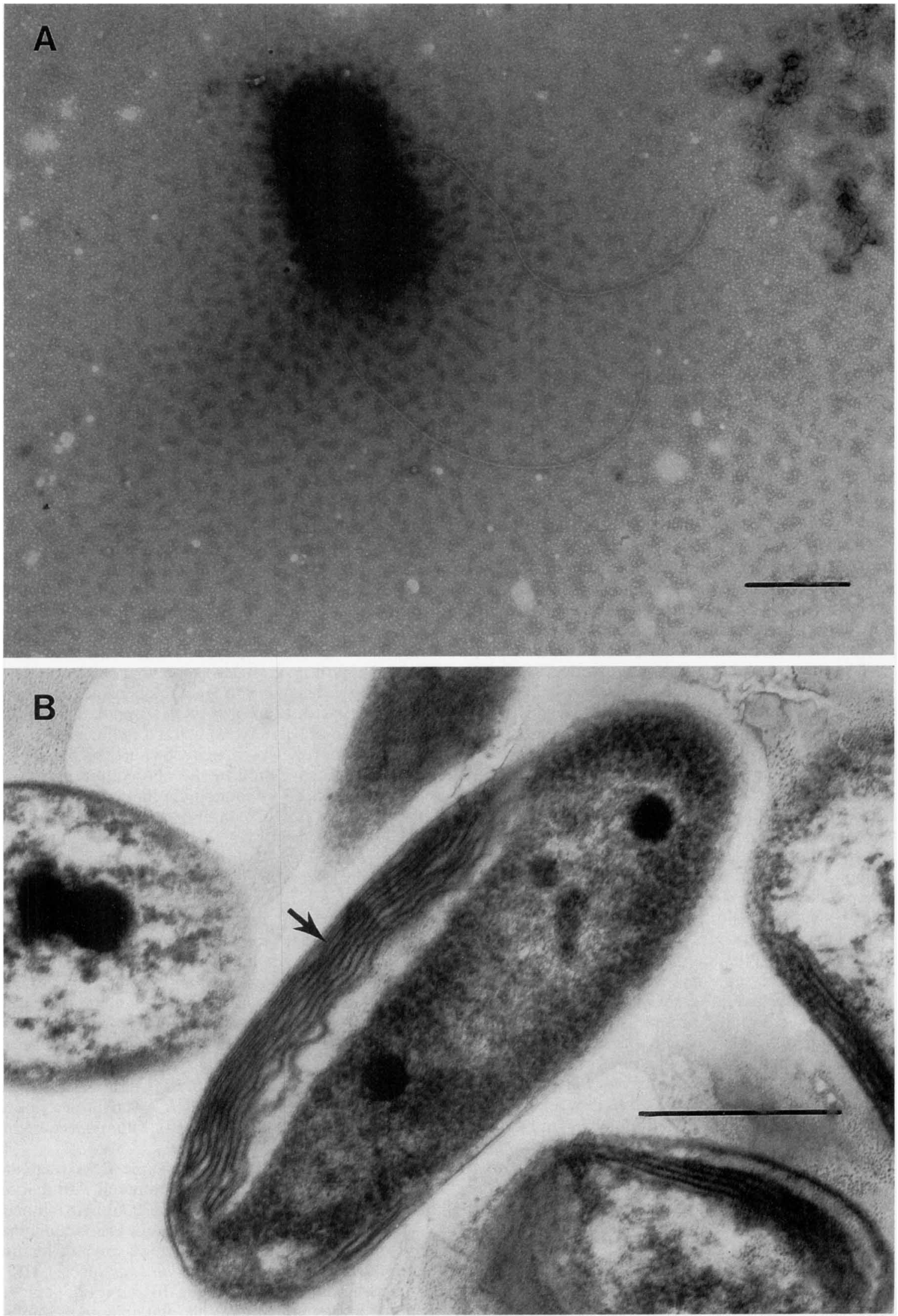

FIG. 2. Electron micrographs of negatively stained cells (A) and ultrathin sections (B) of strain AS130, showing the mode of flagellation and intracytoplasmic membranes (arrow), respectively. Bars, $1 \mu \mathrm{m}$ (A) and $0.5 \mu \mathrm{m}$ (B). 


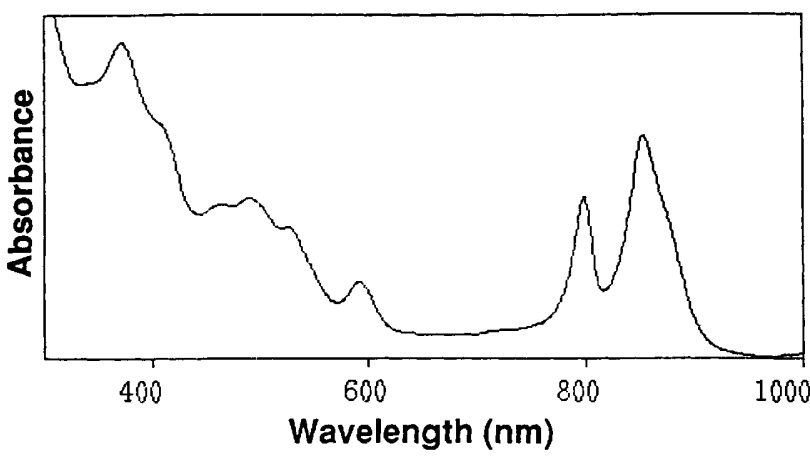

FIG. 3. Absorption spectrum of the cell extract of strain AS130.

Phototrophic purple nonsulfur bacteria were quantitatively isolated from the sludge by using the agar plating technique with the GasPak anaerobic system according to previously described procedures (10), in which malate and Casamino Acids were used as carbon sources. After 10 days of incubation at $28^{\circ} \mathrm{C}$ in the light, the sludge gave $1.3 \times 10^{5} \mathrm{CFU}$ of the purple nonsulfur bacteria per mg (dry weight), a count similar to those previously recorded for activated sludge $(10,31)$. Most of the colonies detected were red or brown and appeared to resemble $R$. palustris, $R$. blastica, and Rhodobacter sphaeroides on the basis of their pigmentation and cell morphology observed under a phase-contrast microscope. Among the colonies detected, there were a few tiny pink colonies which interested us in their taxonomic aspects. Thus, two representatives of the single pink colonies were picked from the plate for standard purification and were designated AS130 and AS140.

Morphology and ultrastructure. Strains AS130 and AS140 had gram-negative, rod-shaped cells measuring 0.8 to $1.0 \mu \mathrm{m}$ in width and 2.0 to $3.0 \mu \mathrm{m}$ in length (Fig. 1A). The cells divided asymmetrically by budding with a division tube which occurred between the mother and daughter cells, and they formed rosette-like clusters in older cultures. In these respects, the isolates were similar to $R$. palustris (Fig. 1C) and $R$. viridis, but with respect to cell size they most closely resembled $R$. rosea (Fig. 1B) among members of this genus. Both of the new isolates were motile by means of polar, subpolar, or randomly distributed flagella; the majority of cells had two flagella located in subpolar areas (Fig. 2A). Electron microscopy of ultrathin sections revealed that phototrophically grown cells of the isolates formed intracytoplasmic membranes of the lamellar type typical of the genus Rhodopseudomonas (Fig. 2B).

Photopigments. The isolates produced pink, lens-shaped colonies in agar media and pink cell suspensions in liquid media when grown under anaerobic phototrophic growth conditions, like $R$. rosea. The cell extract of strain AS130 had absorption maxima at $373,466,491,527,592,799$, and $855 \mathrm{~nm}$, indicating the presence of bacteriochlorophyll $a$ and carotenoids of the normal spirilloxanthin series (Fig. 3). Similar absorption spectra were recorded for strain AS140 and $R$. rosea $941^{\mathrm{T}}$ (data not shown). Our isolates as well as $R$. rosea were colorless when grown aerobically in darkness.

Growth. Strains AS130 and AS140 were facultatively aerobic phototrophs that were able to grow anaerobically in the light or aerobically in darkness at full atmospheric oxygen tension. Of particular interest was that the new isolates had the ability to grow anaerobically in darkness with nitrate as the terminal electron acceptor with concomitant production of nitrogen gas, thereby confirming their capacity for complete denitrification.
Anaerobic growth in darkness by nitrate respiration was also observed for $R$. rosea but not for any other Rhodopseudomonas strains tested. Comparative growth rates and cell yields of strain AS130 and $R$. rosea $941^{\mathrm{T}}$ under different growth conditions are shown in Table 1 . The doubling times of both test strains under phototrophic growth conditions were more than $6 \mathrm{~h}$, suggesting that they grow phototrophically at relatively slow rates compared with other known species of the genus Rhodopseudomonas.

Physiological and biochemical characteristics. The isolates showed a strong tendency for photoorganotrophy with simple organic compounds as electron donor and carbon sources, and they resembled $R$. rosea in photoassimilation patterns with organic substrates. Good carbon sources were acetate, lactate, pyruvate, succinate, fumarate, malate, and yeast extract. Moderate growth occurred with propionate, butyrate, valerate, caproate, citrate, tartrate, Casamino Acids, and peptone. No significant growth was found with formate, glycolate, malonate, benzoate, fatty acids containing six or more carbon atoms, arabinose, xylose, rhamnose, fructose, glucose, mannose, galactose, dulcitol, mannitol, sorbitol, glycerol, methanol, ethanol, propanol, alanine, asparagine, aspartate, glutamate, or leucine. The isolates did not appear to utilize sulfide as the electron donor, because they grew more slowly in PYS medium supplemented with $0.1 \mathrm{mM}$ sulfide than in the medium without sulfide. Photoautotrophic growth occurred with $2 \mathrm{mM}$ thiosulfate but not with $0.5 \mathrm{mM}$ sulfide as the electron donor in the presence of $0.01 \%$ yeast extract.

Other phenotypic characteristics which our isolates shared were as follows. The optimal temperature for growth was 30 to $35^{\circ} \mathrm{C}$. The $\mathrm{pH}$ range for growth was 6.0 to 8.5 , with a $\mathrm{pH}$ optimum of 7.0. Growth occurred in the absence of added $\mathrm{NaCl}$. No or little growth was found at $\mathrm{NaCl}$ concentrations of $1 \%$ or more. Thiamine and $p$-aminobenzoic acid were required as growth factors, but growth was stimulated considerably by the addition of $0.01 \%$ yeast extract. Sulfate was assimilated as the sulfur source. The capacity for nitrogen fixation seemed to be absent, as suggested by the observation that no hydrogen gas was produced in ammonium-limited PYS medium under phototrophic growth conditions. Hydrolysis of gelatin and Tween 80 was negative.

We reexamined $R$. rosea $941^{\mathrm{T}}$ for the physiological and biochemical properties noted above and found some differences between the results of Janssen and Harfoot (17) and ours. The original report for $R$. rosea mentioned that this organism was able to utilize glucose and glycerol as carbon sources, but our attempts to demonstrate this gave negative results. Also, the previous study showed that $R$. rosea did not photoassimilate valerate, while we found weak growth with valerate. Moreover, we noted that $R$. rosea failed to grow at a $\mathrm{pH}$ of less than 6.0, which differs from the results of Janssen and Harfoot (17), who reported it to grow at $\mathrm{pH}$ 5.5. The results of comparative phenotypic studies showed dissimilarities between our isolates and $R$. rosea in such physiological properties as growth at $\mathrm{pH} 6.0$, vitamin requirement, and caproate utilization.

Quinone composition and genomic DNA relatedness. The quinone profiles of the isolates compared with that of $R$. rosea are shown in Table 2. Strains AS130 and AS140 and $R$. rosea $941^{\mathrm{T}}$ produced both ubiquinones and rhodoquinones as primary quinone components, a chemotaxonomic feature distinct from those of other Rhodopseudomonas species. HPLC experiments showed that ubiquinone-10 and rhodoquinone- 10 constituted more than $90 \%$ of the total ubiquinone and rhodoquinone fractions, respectively, in all these strains.

Table 2 also shows the DNA base compositions of and 
TABLE 1. Growth responses to different environmental conditions by strain AS130 and $R$. rosea

\begin{tabular}{|c|c|c|c|c|c|}
\hline \multirow{2}{*}{$\begin{array}{c}\text { Growth } \\
\text { conditions }\end{array}$} & \multirow{2}{*}{$\begin{array}{l}\text { Addition } \\
\text { of nitrate }\end{array}$} & \multicolumn{2}{|c|}{ Strain AS130 } & \multicolumn{2}{|c|}{ R. rosea $941^{\mathrm{T}}$} \\
\hline & & $\begin{array}{l}t_{D}^{a} \\
(\mathrm{~h})\end{array}$ & $\begin{array}{l}\text { Relative cell } \\
\text { yield }^{b}(\%)\end{array}$ & $t_{D}$ & $\begin{array}{c}\text { Relative cell } \\
\text { yield }(\%)\end{array}$ \\
\hline \multirow[t]{2}{*}{ Anaerobic, light } & - & 6.5 & 100 & 10 & 100 \\
\hline & + & 7.0 & 100 & 11 & 63 \\
\hline Aerobic, dark & - & 6.3 & 74 & 10 & 64 \\
\hline Anaerobic, dark & + & 31 & 13 & 22 & 44 \\
\hline
\end{tabular}

genomic DNA relatedness among the test organisms. The $\mathrm{G}+\mathrm{C}$ contents of the genomic DNAs of strains AS130 and AS140 were, respectively, 69.7 and $69.6 \mathrm{~mol} \%$, which are considerably higher than those recorded for $R$. rosea $941^{\mathrm{T}}$ and other reference organisms. The two new isolates were highly related to each other but showed low levels of DNA-DNA hybridization (less than $40 \%$ ) to $R$. rosea $941^{\mathrm{T}}$. Much lower levels of genomic DNA relatedness were found between our isolates and all other test strains of Rhodopseudomonas species.

Phylogenetic relationships. The continuous nucleotide sequences of $16 \mathrm{~S}$ rDNA fragments amplified from one of the new isolates (strain AS130), $R$. palustris, $R$. rosea, and $R$. viridis were determined. The sequences determined ranged from 1,407 to 1,413 residues, representing $95 \%$ of the entire $16 \mathrm{~S}$ rRNA gene. Strain AS130 differed from the other test organisms in having a $16 \mathrm{~S}$ rRNA secondary structure with two-pairshorter stems around position 80 (E. coli numbering). The $16 \mathrm{~S}$ rDNA sequences of these organisms were compared with the sequences from representative species of phototrophs and their nonphototrophic relatives which belong to the alpha subclass of the Proteobacteria. Table 3 shows levels of sequence similarity for each pair of the organisms and evolutionary distance $\left(K_{\text {nuc }}\right)$ values calculated for the alignable 1,238 positions of all sequences of the entire set. Strain AS130 was closely related to $R$. rosea at a similarity level of $98.3 \%\left(K_{\text {nuc }}=\right.$ 0.0129 ) but showed much lower affinities to all other Rhodopseudomonas species compared ( $<95 \%$ similarity).

Almost complete sequences of the $16 \mathrm{~S}$ rRNAs of $R$. palustris GH and DSM $123^{\mathrm{T}}$ have been reported previously by Woese
(GenBank accession number M59068) and Orso et al. (24) (GenBank accession number L11664), respectively. As expected, the $16 \mathrm{~S}$ rRNA gene sequence of $R$. palustris determined in this study was almost identical to the sequence for strain $\mathrm{GH}$, except for a number of undetermined positions included in the latter sequence. On the other hand, it was strange that the sequence for ATCC $17001^{\mathrm{T}}$ that we determined differed from the sequence for DSM $123^{\mathrm{T}}$ in 38 positions of 1,411 residues compared, corresponding to $97.3 \%$ similarity. This similarity level is too low to be due to different sequencing methods used or to sequencing errors. The previous data on $R$. palustris might have resulted from mislabeling of the strain or sequencing sample.

On the basis of the corrected distance values shown in Table 3 , a neighbor-joining phylogenetic tree was reconstructed (Fig. 4). Strain AS130 and $R$. rosea formed a tight cluster distinct from the type species $R$. palustris and all other species of Rhodopseudomonas compared. The monophyletic nature of this cluster was supported by bootstrapping in $100 \%$ of the 1,000 trees generated. The $R$, rosea cluster was linked to $R$. viridis as the phylogenetic neighbor, and the cluster including $R$. viridis as the sister group also proved to be stable $(90.3 \%$ support by bootstrapping). The topology of the tree confirmed phylogenetic divergence of Rhodopseudomonas species within the alpha-2 subclass of the Proteobacteria.

\section{DISCUSSION}

The results of the present study have provided taxonomic and phylogenetic information concerning the new pink-pigmented isolates of the phototrophic bacteria and have expanded the previous results obtained with $R$. rosea (17). Our results show that the new isolates make up a phenotypically and genotypically coherent group that falls into a single species. They are facultatively photoheterotrophic, have a budding type of cell division, and produce photosynthetic membrane systems of the lamellar type together with bacteriochlorophyll $a$ and carotenoids of the spirilloxanthin series, features conforming to the definition of the genus Rhodopseudomonas $(16,32)$. Phenotypically, the new isolates most closely resemble $R$. rosea among species of this genus. The important characteristics that are common between the isolates and $R$. rosea are cell size (0.8 to $1.0 \mu \mathrm{m}$ in width), pink pigmentation, relatively slow phototrophic growth, denitrifica-

TABLE 2. Quinone profiles of and genomic DNA relatedness between the isolates and known species of the genus Rhodopseudomonas

\begin{tabular}{|c|c|c|c|c|c|c|c|c|}
\hline \multirow[b]{2}{*}{ Organism } & \multicolumn{3}{|c|}{ Major quinone homolog ${ }^{a}$} & \multirow{2}{*}{$\underset{(\mathrm{mol} \%)^{b}}{\mathbf{G}+\mathrm{C}}$} & \multicolumn{4}{|c|}{$\%$ Hybridization of labeled DNA from: } \\
\hline & $\mathrm{Q}$ & RQ & MK & & AS130 & AS140 & R. rosea $941^{\mathrm{T}}$ & $\begin{array}{c}\text { R. palustris } \\
\text { ATCC } 17001^{\mathrm{T}}\end{array}$ \\
\hline Strain AS130 & 10 & 10 & & 69.7 & 100 & 105 & 39 & 14 \\
\hline Strain AS140 & 10 & 10 & & 69.6 & 98 & 100 & & \\
\hline R. rosea $941^{\mathrm{T}}$ & 10 & 10 & & 66.8 & 34 & 40 & 100 & 11 \\
\hline R. palustris ATCC $17001^{\mathrm{T}}$ & 10 & & & 65.0 & 11 & 10 & 11 & 100 \\
\hline R. palustris RS22 & 10 & & & 64.9 & 13 & & & \\
\hline R. palustris SA37 & 10 & & & 64.6 & 11 & & & \\
\hline R. palustris $\mathrm{Tb}$ & 10 & & & 64.6 & 9 & & & \\
\hline R. palustris HLS2 & 10 & & & 64.8 & 11 & & & \\
\hline R. viridis ATCC $19567^{\mathrm{T}}$ & 9 & & 9 & 66.5 & 17 & 15 & 20 & \\
\hline R. acidophila ATCC $25092^{\mathrm{T}}$ & 10 & 10 & 10 & 65.1 & 9 & 8 & 12 & \\
\hline$R$. marina DSM $2698^{\mathrm{T}}$ & 10 & & 10 & 63.6 & 7 & 8 & 6 & \\
\hline R. blastica ATCC $33485^{\mathrm{T}}$ & 10 & & & 65.5 & 5 & 5 & 6 & \\
\hline
\end{tabular}

\footnotetext{
${ }^{a} \mathrm{Q}$, ubiquinone; $\mathrm{RQ}$, rhodoquinone; $\mathrm{MK}$, menaquinone. Information for the new isolates and $R$. rosea is from this study, and that for the other organisms is from references 8 and 11 .

${ }^{b}$ Information for the new isolates and $R$. rosea is from this study, and that for the other organisms is from references 11 and 15.
} 


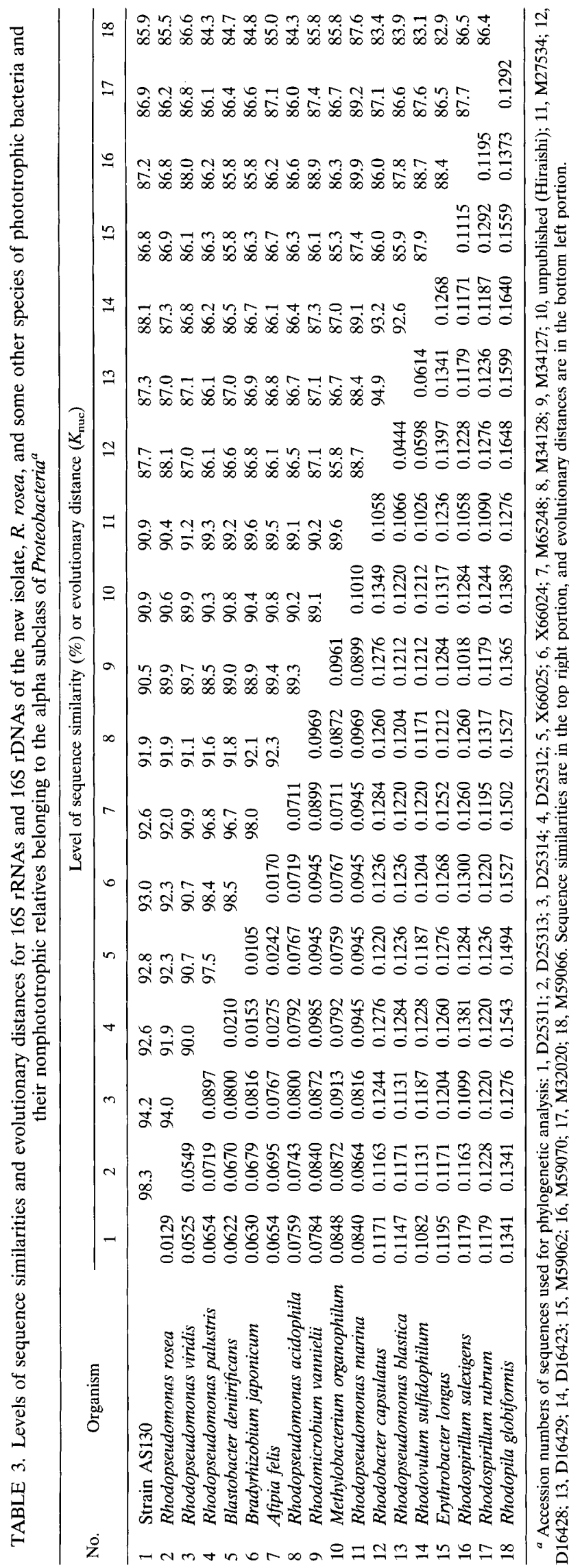

tion, photoassimilation of tartrate, utilization of thiosulfate but not sulfide, and production of ubiquinone-10 and rhodoquinone-10 as major quinones. By the combination of these features, our isolates and $R$. rosea are clearly differentiated from all other species of the genus Rhodopseudomonas.

To date, the capacity for complete denitrification has been found in some strains of Rhodobacter sphaeroides $(25,28,30)$ and $R$. palustris (21) among the phototrophic bacteria. In the present study, however, we did not find denitrifying growth in any test strains of $R$. palustris. In view of the fact that the taxonomic properties of the denitrifying strains of $R$. palustris were not described in detail (21), it would be interesting to study the taxonomic relationships of these strains to our isolates and $R$. rosea.

Although the new isolates share a number of characteristics with $R$. rosea, as described above, the former group differs clearly from the latter in the following characteristics: budding types (tube or sessile), rosette formation, growth at $\mathrm{pH} 6.0$, caproate utilization, vitamin requirement, and DNA base composition. In addition, the results of genomic DNA hybridization studies demonstrate that the isolates are genetically different from $R$. rosea at the species level and have more distant genealogical relationships to all other Rhodopseudomonas species compared. These phenotypic and genotypic data are sufficient to justify classification of our isolates as a new species related to $R$. rosea. In this study we did not examine some species of the genus Rhodopseudomonas, such as $R$. julia (22) and $R$. sulfoviridis (19), from genotypic viewpoints. However, it is easy to differentiate the new isolates from these species by a number of phenotypic differences and by their natural habitats.

According to the phenotypic criteria for the current taxonomy of the purple nonsulfur bacteria $(16,32)$, our isolates may be classified as a new species of the genus Rhodopseudomonas. However, attention should be paid to the fact that the genus Rhodopseudomonas itself is an assemblage of phylogenetically heterogeneous species. The present study and other phylogenetic studies by $16 \mathrm{~S}$ rRNA cataloging $(29,34)$ and sequencing $(24,33,35)$ demonstrate that the type species $R$. palustris is more closely related to some chemotrophic taxa, i.e., Afipia felis, Bradyrhizobium japonicum, Blastobacter denitrificans, and Nitrobacter winogradskyi, than to any of the other Rhodopseudomonas species for which sequence formation is available. Our data also show that the new isolates and $R$. rosea belong to a lineage distinct from that of $R$. palustris and all other Rhodopseudomonas species compared. Accordingly, the established species of the genus Rhodopseudomonas can no longer be placed in a single genus on phylogenetic grounds.

In view of the unsatisfactory taxonomic status of the genus Rhodopseudomonas and the resultant need for improvement of its taxonomy, it is more appropriate to incorporate our isolates together with $R$. rosea into a new genus than to place them in the genus Rhodopseudomonas. The present results have demonstrated that $R$. viridis is the closest relative of the phylogenetic group encompassing our isolates and $R$. rosea. However, phenotypic similarities and the level of sequence homology between the former species and the latter group are low enough to warrant different generic allocations. Here we propose to transfer $R$. rosea to the new genus Rhodoplanes as Rhodoplanes roseus gen. nov., comb. nov. (type species) and to designate strains AS130 and AS140 members of a new species of this genus, for which we propose the name Rhodoplanes elegans sp. nov. Diagnostic characteristics of members of the new genus Rhodoplanes and some species of the genus Rhodopseudomonas are summarized in Table 4.

The available phylogenetic and chemotaxonomic informa- 


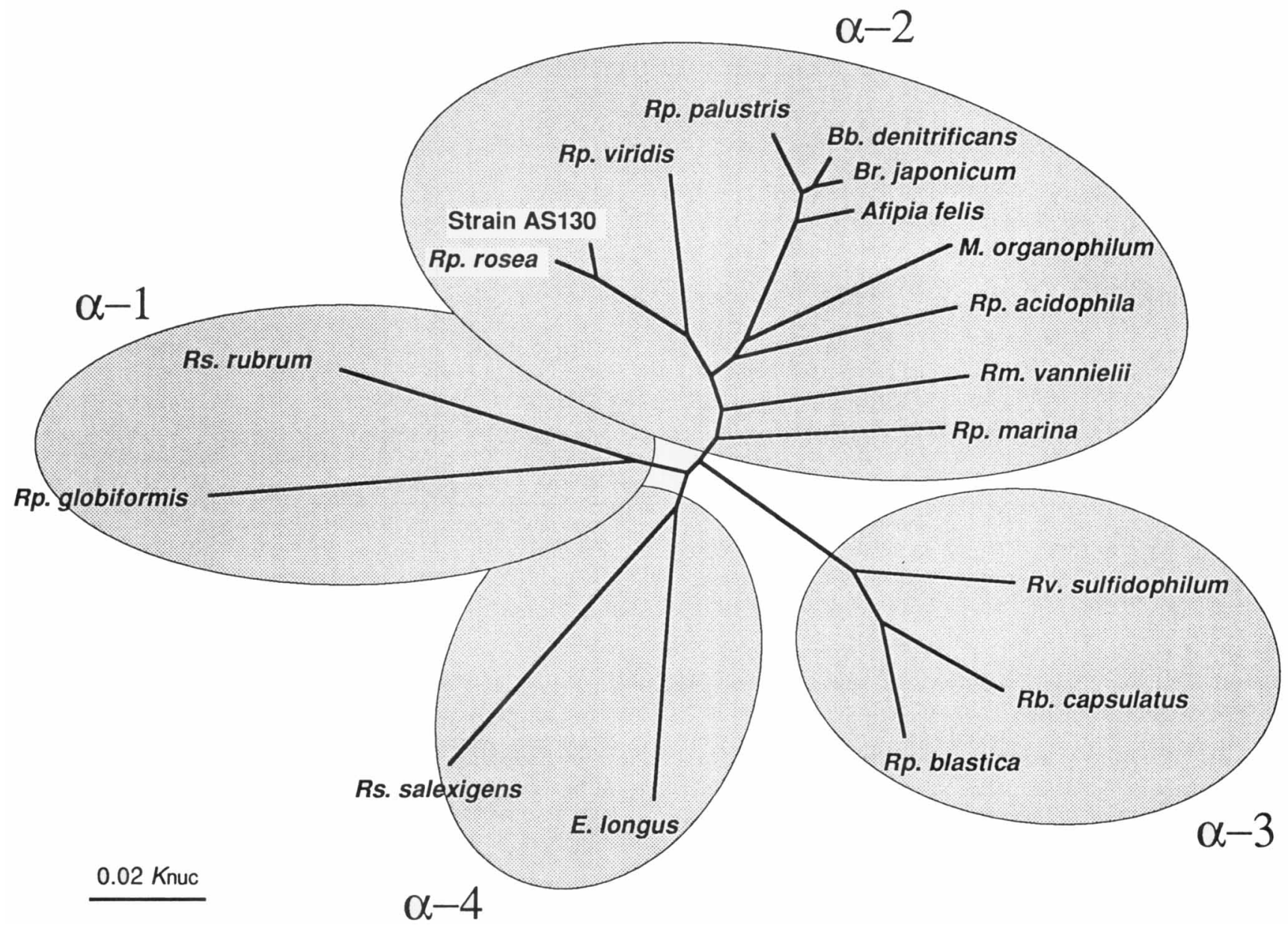

FIG. 4. Unrooted distance matrix tree showing phylogenetic affiliations of strain AS130, R. rosea, and other species of phototrophic bacteria and their nonphototrophic relatives within the alpha subclass of the Proteobacteria. For organism names and accession numbers for sequences used, see Table 3.

tion strongly suggests the need for rearrangement and nomenclatural revisions of Rhodopseudomonas species within the alpha-2 subclass of the Proteobacteria. Our proposal for the transfer of $R$. rosea to the new genus Rhodoplanes is the first step in this direction. Probably all other Rhodopseudomonas species, except the type species $R$. palustris, would be split up into different new genera via further systematic studies in the near future. Following this and taxonomic revisions for related chemotrophic taxa, e.g., Blastobacter, Bradyrhizobium, and Nitrobacter, the description of the genus Rhodopseudomonas should be emended.

Description of Rhodoplanes gen. nov. Rhodoplanes (Rho.do. plan'es. Gr. n. rhodos, rose; Gr. n. planes, a wanderer; Gr. n. Rhodoplanes, a red wanderer). Cells are gram-negative rods. Multiply by budding and asymmetric cell division. Motile by means of polar, subpolar, or randomly distributed flagella. Facultative phototrophs growing anaerobically in the light or aerobically in darkness. Anaerobic growth in darkness by nitrate respiration is also possible; denitrification positive. Photosynthetic cultures are pink, while aerobic chemotrophic cultures are colorless. Phototrophically grown cells contain intracytoplasmic membranes of the lamellar type together with bacteriochlorophyll $a$ and carotenoids of the normal spirilloxanthin series. Mesophilic, neutrophic, and nonhalophilic. Growth in the presence of $\mathrm{NaCl}$ at a concentration of $1 \%$ or more is inhibited. Photoorganotrophy with simple organic compounds is the preferred mode of growth. Photoautotrophic growth occurs with thiosulfate as the electron donor in the presence of $0.01 \%$ yeast extract. Sulfide may not be utilized. Hydrolysis of gelatin and Tween 80 is negative. Ubiquinone-10 and rhodoquinone-10 are present as major quinones. The $\mathrm{G}+\mathrm{C}$ content of DNA ranges from 66 to $70 \mathrm{~mol} \%$. Phylogenetic position is the alpha-2 subclass of Proteobacteria.

Habitats: freshwater and wastewater environments.

Type species: Rhodoplanes roseus.

Description of Rhodoplanes roseus comb. nov. Rhodoplanes roseus (Rhodopseudomonas rosea Janssen and Harfoot 1991) (ro'se.us. L. adj. roseus, rose-colored, pink). The characteristics are the same as the characteristics described above for the genus. The following additional properties are based on the information from the previous report (17) and this study. Cells are $1.0 \mu \mathrm{m}$ wide and 1.8 to $2.5 \mu \mathrm{m}$ long. Reproduce by budding without a division tube. Rosette formation is not found. Absorption maxima of cell extracts are at 373, 468, 493, 530, 593,801 , and $854 \mathrm{~nm}$. The $\mathrm{pH}$ range for growth is 6.5 to 8.0 . No growth occurs at $\mathrm{pH}$ 6.0. Niacin is required as a growth factor, but growth is stimulated considerably by addition of $0.01 \%$ yeast extract. Utilizable electron donor and carbon sources for phototrophic growth are acetate, propionate, butyrate, valerate, lactate, pyruvate, succinate, fumarate, malate, citrate, 
TABLE 4. Characteristics of members of Rhodoplanes gen. nov. and some species of the genus Rhodopseudomonas ${ }^{a}$

\begin{tabular}{|c|c|c|c|c|c|c|}
\hline \multirow{2}{*}{ Characteristic } & \multicolumn{2}{|c|}{ Rhodoplanes } & \multicolumn{4}{|c|}{ Rhodopseudomonas } \\
\hline & R. roseus & R. elegans & R. acidophila & R. marina & R. palustris & R. viridis \\
\hline Cell diameter $(\mu \mathrm{m})$ & 1.0 & $0.8-1.0$ & $1.0-1.3$ & $0.7-0.9$ & $0.6-0.9$ & $0.6-0.9$ \\
\hline Type of budding & Sessile & Tube & Sessile & Sessile & Tube & Tube \\
\hline Rosette formation & - & + & - & - & + & + \\
\hline Color of cultures & Pink & Pink & Red & Pink & Red & Green \\
\hline Bacteriochlorophyll & $a$ & $a$ & $a$ & $a$ & $a$ & $b$ \\
\hline Salt requirement & - & - & - & + & - & - \\
\hline Denitrification & + & + & - & - & $-1+$ & - \\
\hline Vitamin required & Niacin & $\mathrm{p}-\mathrm{ABA}+$ thiamine & None & ND & p-ABA (+ biotin) & p-ABA + biotin \\
\hline \multicolumn{7}{|l|}{ Utilization of: } \\
\hline Benzoate & - & - & - & - & + & - \\
\hline Citrate & + & + & - & $-1+$ & + & - \\
\hline Tartrate & + & + & - & - & - & - \\
\hline Sulfide & - & - & - & + & + & - \\
\hline Major quinone(s) & Q-10, RQ-10 & Q-10, RQ-10 & Q-10, RQ-10, MK-10 & Q-10, MK-10 & Q-10 & Q-9, MK-9 \\
\hline $\mathrm{G}+\mathrm{C}(\mathrm{mol} \%)$ & $66\left(T_{m}\right), 66.8(\mathrm{HPLC})$ & 69.6-69.7 (HPLC) & $62.2-66.8(\mathrm{Bd})$ & $61.5-63.8\left(T_{m}\right)$ & $64.5-65.5$ (HPLC) & $66.3-71.4(\mathrm{Bd})$ \\
\hline Habitat & Freshwater & Freshwater & Freshwater & Seawater & Freshwater & Freshwater \\
\hline
\end{tabular}

${ }^{a}$ Symbols and abbreviations: + , positive; - , negative; $-/+$, most strains negative and some strains positive; p-ABA, $p$-aminobenzoic acid; ND, not determined; $(+$ biotin), biotin required by a few strains only; $\mathrm{Q}$, ubiquinone; RQ, rhodoquinone; MK, menaquinone; Bd, buoyant density. Information is from references $3,8,11,15$, 17,26 , and 32 and this study.

tartrate, Casamino Acids, yeast extract, and peptone. The following organic compounds are not utilized: formate, longchain fatty acids with more than five carbon atoms, glycolate, malonate, benzoate, arabinose, xylose, rhamnose, fructose, glocose, mannose, galactose, dulcitol, mannitol, sorbitol, glycerol, methanol, ethanol, propanol, alanine, aspartate, asparagine, glutamate, and leucine. The $\mathrm{G}+\mathrm{C}$ content of the DNA is $66.8 \mathrm{~mol} \%$ (by HPLC) and $66 \mathrm{~mol} \%$ (by $T_{m}$ ).

Isolated from freshwater lake sediment.

The type strain is DSM 5909 (Janssen and Harfoot 941).

Description of Rhodoplanes elegans sp. nov. Rhodoplanes elegans (e'le.gans. L. adj. elegans, choice, elegant). The characteristics are the same as the characteristics described above for the genus. Additional properties are as follows. Cells are 0.8 to $1.0 \mu \mathrm{m}$ wide and 2.0 to $3.5 \mu \mathrm{m}$ long. Reproduce by budding with a division tube occurring between the mother and daughter cells. Rosettes and clusters are formed in older cultures. Absorption maxima of cell extracts are at 373, 466, $491,527,592,799$, and $855 \mathrm{~nm}$. The $\mathrm{pH}$ range for phototrophic growth is 6.0 to 8.5 . Thiamine and $p$-aminobenzoic acid are required as growth factors. The following organic compounds are photoassimilated: acetate, propionate, butyrate, valerate, caproate, lactate, pyruvate, succinate, fumarate, malate, citrate, tartrate, Casamino Acids, and yeast extract. The following organic compounds are not utilized: formate, long-chain fatty acids with more than six carbon atoms, glycolate, malonate, benzoate, arabinose, xylose, rhamnose, fructose, glucose, mannose, galactose, dulcitol, mannitol, sorbitol, glycerol, methanol, ethanol, propanol, alanine, aspartate, asparagine, glutamate, and leucine. The $\mathrm{G}+\mathrm{C}$ content of the DNA is 69.6 to $69.7 \mathrm{~mol} \%$ (by HPLC).

Isolated from activated sludge.

The type strain is AS130, which has been deposited in the Japan Collection of Microorganisms, RIKEN, Wako, Japan, as $R$. elegans JCM 9224.

\section{ACKNOWLEDGMENT}

We thank C. G. Harfoot for supplying the culture of $R$. rosea.

\section{REFERENCES}

1. Brosius, J., J. L. Palmer, J. P. Kennedy, and H. F. Noller. 1978. Complete nucleotide sequence of a 16S ribosomal RNA gene from Escherichia coli. Proc. Natl. Acad. Sci. USA 75:4801-4805.

2. De Ley, J. 1992. The Proteobacteria: ribosomal RNA cistron similarities and bacterial taxonomy, p. 2111-2140. In A. Balows, H. G. Trüper, M. Dworkin, W. Harder, and K. H. Schleifer (ed.), The prokaryotes, 2nd ed. Springer-Verlag, Berlin.

3. Drews, G., and P. Giesbrecht. 1966. Rhodopseudomonas viridis, nov. spec., ein neu isoliertes, obligat phototrophes Bakterium. Arch. Mikrobiol. 53:255-262.

4. Ezaki, T., S. Dejsirilert, H. Yamamoto, N. Takeuchi, S. Liu, and E. Yabuuchi. 1988. Simple and rapid genetic identification of Legionella species with photobiotin-labeled DNA. J. Gen. Appl. Microbiol. 34:191-199.

5. Felsenstein, J. 1985. Confidence limits on phylogenies: an approach using the bootstrap. Evolution 39:783-791.

6. Higgins, D. G., A. J. Bleasby, and R. Fuchs. 1992. CLUSTAL V: improved software for multiple sequence alignment. Comp. Appl. Biosci. 8:189-191.

7. Hiraishi, A. 1992. Direct automated sequencing of $16 \mathrm{~S}$ rDNA amplified by polymerase chain reaction from bacterial cultures without DNA purification. Lett. Appl. Microbiol. 15:210-213.

8. Hiraishi, A., and Y. Hoshino. 1984. Distribution of rhodoquinone in Rhodospirillaceae and its taxonomic implications. J. Gen. Appl. Microbiol. 30:435-448.

9. Hiraishi, A., Y. Hoshino, and T. Satoh. 1991. Rhodoferax fermentans gen. nov., sp. nov., a phototrophic purple nonsulfur bacterium previously referred to as the "Rhodocyclus gelatinosus-like" group. Arch. Microbiol. 155:330-336.

10. Hiraishi, A., and H. Kitamura. 1984. Distribution of phototrophic purple nonsulfur bacteria in activated sludge systems and other aquatic environments. Bull. Jpn. Soc. Sci. Fish. 50:1929-1937.

11. Hiraishi, A., T. S. Santos, J. Sugiyama, and K. Komagata. 1992. Rhodopseudomonas rutila is a later subjective synonym of Rhodopseudomonas palustris. Int. J. Syst. Bacteriol. 42:186-188.

12. Hiraishi, A., J.-L. Shi, and H. Kitamura. 1989. Effects of organic nutrient strength on the purple nonsulfur bacterial content and metabolic activity of photosynthetic sludge for wastewater treatment. J. Ferment. Bioeng. 68:269-276.

13. Hiraishi, A., Y. K. Shin, Y. Ueda, and J. Sugiyama. 1994. Automated sequencing of PCR-amplified 16S rDNA on "Hydrolink" gels. J. Microbiol. Methods 19:145-154.

14. Hiraishi, A., and Y. Ueda. 1994. Intrageneric structure of the genus 
Rhodobacter: transfer of Rhodobacter sulfidophilus and related marine species to the genus Rhodovulum gen. nov. Int. J. Syst. Bacteriol. 44:15-23.

15. Imhoff, J. F. 1983. Rhodopseudomonas marina sp. nov., a new marine phototrophic purple bacterium. Syst. Appl. Microbiol. 4:512-521.

16. Imhoff, J. F., H. G. Trüper, and N. Pfennig. 1984. Rearrangements of the species and genera of the phototrophic "purple nonsulfur bacteria." Int. J. Syst. Bacteriol. 34:340-343.

17. Janssen, P. H., and C. G. Harfoot. 1991. Rhodopseudomonas rosea sp. nov., a new purple nonsulfur bacterium. Int. J. Syst. Bacteriol. 41:26-30.

18. Kawasaki, H., Y. Hoshino, A. Hirata, and K. Yamasato. 1993. Is intracytoplasmic membrane structure a generic criterion? It does not coincide with phylogenetic interrelationships among phototrophic purple nonsulfur bacteria. Arch. Microbiol. 160:358-362.

19. Keppen, O. I., and V. M. Gorlenko. 1975. A new species of purple budding bacteria containing bacteriochlorophyll $b$. Mikrobiologiya 44:258-264. (In Russian.)

20. Kimura, M. 1980 . A simple method for estimating evolutionary rates of base substitution through comparative studies of nucleotide sequences. J. Mol. Evol. 16:111-120.

21. Klemme, J. H., I. Chyla, and M. Preuss. 1980. Dissimilatory nitrate reduction by strains of the facultative phototrophic bacterium Rhodopseudomonas palustris. FEMS Microbiol. Lett. 9:137-140.

22. Kompantseva, E. I. 1989. A new species of the budding purple bacterium Rhodopseudomonas julia sp. nov. Mikrobiogiya 58:319325. (In Russian.)

23. Marmur, J. 1961. A procedure for the isolation of deoxyribonucleic acid from micro-organisms. J. Mol. Biol. 3:208-218.

24. Orso, S., M. Gouy, E. Navarro, and P. Normand. 1994. Molecular phylogenetic analysis of Nitrobacter spp. Int. J. Syst. Bacteriol. 44:83-86.

25. Pellelin, N. B., and H. Gest. 1983. Diagnostic features of the photosynthetic bacterium Rhodopseudomonas sphaeroides. Curr. Microbiol. 9:339-344.
26. Pfennig, N. 1969. Rhodopseudomonas acidophila, sp. n., a new species of budding purple nonsulfur bacteria. J. Bacteriol. 99:597602.

27. Saitou, N., and M. Nei. 1987. The neighbor-joining method: a new method for reconstructing phylogenetic trees. Mol. Biol. Evol. 4:406-425.

28. Satoh, T., Y. Hoshino, and H. Kitamura. 1976. Rhodopseudomonas sphaeroides forma sp. denitrificans, a denitrifying strain as a subspecies of Rhodopseudomonas sphaeroides. Arch. Microbiol. 108:265-269.

29. Seewaldt, E., K. H. Schleifer, E. Bock, and E. Stackebrandt. 1982. The close phylogenetic relationship of Nitrobacter and Rhodopseudomonas palustris. Arch. Microbiol. 131:287-290.

30. Shen, J., and O. Hirayama. 1991. Hydrogen photoproduction and denitrification by photosynthetic bacteria isolated from lake $\mathrm{Na}$ kaumi and its vicinity. J. Ferment. Bioeng. 72:338-342.

31. Siefert, E., R. L. Irgens, and N. Pfennig. 1978. Phototrophic purple and green bacteria in a sewage treatment plant. Appl. Environ. Microbiol. 35:38-44.

32. Trüper, H. G., and J. F. Imhoff. 1989. Genus Rhodopseudomonas Kluyver and van Niel in Czurda and Maresch 1937, 119 AL, p. 1672-1677. In J. T. Staley, M. P. Bryant, N. Pfennig, and J. G. Holt (ed.), Bergey's manual of systematic bacteriology, vol. 3. The Williams \& Wilkins Co., Baltimore.

33. Woese, C. R. 1987. Bacterial evolution. Microbiol. Rev. 51:221271.

34. Woese, C. R., E. Stackebrandt, W. G. Weisburg, B. J. Paster, M. T. Madigan, V. J. Fowler, C. M. Hahn, P. Blanz, R. Gupta, K. H. Nealson, and G. E. Fox. 1984. The phylogeny of purple bacteria: the alpha subdivision. Syst. Appl. Microbiol. 5:315-326.

35. Wong, F. Y. K., E. Stackebrandt, J. K. Ladha, D. E. Fleischman, R. A. Date, and J. A. Fuerst. 1994. Phylogenetic analysis of Bradyrhizobium japonicum and photosynthetic stem-nodulating bacteria from Aeschynomene species grown in separated geographical regions. Appl. Environ. Microbiol. 60:940-946. 